\title{
NEW THIOPYRANO[2,3-d][1,3]THIAZOLE DERIVATIVES AS POTENTIAL ANTIVIRAL AGENTS
}

\author{
N. I. ZELISKO, I. L. DEMCHUK, R. B. LESYK* \\ Danylo Halytsky Lviv National Medical University, Ukraine; \\ *e-mail:dr_r_lesyk@org.lviv.net
}

A series of novel thiopyrano[2,3-d][1,3]thiazole derivatives were synthesized and evaluated for their antiviral activity in vitro within AACF NIAID programme. Compounds were studied towards Dengue Virus Type 2, Venezuelan Equine Encephalitis Virus, Respiratory Syncytial Virus, SARS Coronavirus, Rift Valley Fever Virus, Tacaribe Virus, Influenza Virus Types A and B. Among the tested thiopyrano[2,3-d][1,3]thiazoles, alkyl rel-(5R,5aR,11bS)-2,6-dioxo-3,5a,6,11b-tetrahydro-2H,5H-chromeno[4',3':4,5]thiopyrano[2,3-d] [1,3]thiazole-5-carboxylates $\mathbf{8}$ and $\mathbf{1 1}$ were found to be the most active and showed significant antiviral activity against Influenza Virus Types A H3N2 and H5N1.

Ke y word s: thiopyrano[2,3-d][1,3]thiazoles, screening, antiviral activity.

$\mathrm{V}$

iruses are known as common pathogens that cause a variety of diseases. Search for new efficient antiviral agents is an important worldwide problem among scientists and clinicians, because of rapid emergence of drug resistant strains. Even influenza virus may cause life-threatening events in high-risk patients. To overcome the drawbacks of the current antiviral drugs and to obtain more efficacious drugs, new antiviral drugs with a novel mode of action should be developed. Thiopyrano[2,3- $d][1,3]$ thiazoles have become a promising area of research because of their diverse biological activities, such as anticancer, antitrypanosomal, antimycobacterial, anti-inflammatory and antioxidant ${ }^{1-7}$ (Fig. 1).

In the last two decades, there has been an increase in the number of studies on 4-thiazolidinone derivatives as potential antiviral agents ${ }^{8-13}$. Thiopyrano[2,3-d][1,3] thiazoles could be of special interest as cyclic mimetics of biologically active (including antiviral) 4-thiazolidinones. The aim of present study was to estimate the antiviral activity of new thiopyrano[2,3- $d][1,3]$ thiazole derivatives.

\section{Materials and Methods}

The synthesis of 2-oxo-3,7-dihydro-2H-thiopyrano[2,3- $d]$ thiazole-6-carboxylic acids (1-5) ${ }^{15}$, rel-(5R,5aR,11bS)-2,6-dioxo-3,5a,6,11b-tetrahydro$2 H, 5 H$-chromeno[ $\left[4^{\prime}, 3^{\prime}: 4,5\right]$ thiopyrano[2,3-d][1,3] thiazole-5-carboxylic acids derivatives $(\mathbf{6 - 1 3})^{\mathbf{1 6}}$, 6-carboxymethylene-2-oxo-3,5,6,7-tetrahydro- $2 \mathrm{H}$ - thiopyrano[2,3- $d][1,3]$ thiazole-6-carboxylic acids (14-17) $)^{3}$, 2,6-dioxo-3,5a,6,11b-tetrahydro- $\mathrm{H}, 5 \mathrm{H}$ cromeno[ $\left[4^{\prime}, 3^{\prime}: 4,5\right]$ thiopyrano[2,3-d] thiazol-5a-yl] acetic acids $(\mathbf{1 8 , 1 9})^{3,14}, 7^{\prime}$-(R-phenyl)-1-( ${ }^{1}$-phenyl)$3^{\prime}, 7^{\prime}$-dihydro-2H,2'H,5H-spiro[pyrolidin-3, 6'-

thiopyrano[2,3-d]thiazol]-2,2',5-triones (20-24) ${ }^{3}$ and their characteristics were described in our previous reports. The structure of compounds involved in the study is presented in Fig. 2.

The antiviral activity screening of the compounds was performed at the National Institute of Allergic and Infectious Diseases of the National Institute of Health (Bethesda, MD, USA) within AACF (Antimicrobial Acquisition and Coordinating Facility (http://www.niaid-aacf.org) programme. Antiviral activity was determined against Dengue Virus Type 2 (New Guinea C strain, Vero 76 cell line), Venezuelan Equine Encephalitis Virus (TC-83 strain, Vero cell line), Respiratory Syncytial Virus (A2 strain, MA 104 cell line), SARS Coronavirus (Urbani strain, Vero 76 cell line), Influenza Virus Type A $\mathrm{H}_{5} \mathrm{~N}_{1}$ (Vietnam/1203/2004H strain, MDCK cell line), Rift Valley Fever Virus (MP-12 strain, Vero 76 cell line), Tacaribe Virus (TRVL-11573 strain, Vero cell line), Influenza Virus Type $\mathrm{A}_{3} \mathrm{~N}_{2}$ (Perth/16/2009 strain, MDCK cell line), Influenza Virus Type A $\mathrm{H}_{1} \mathrm{~N}_{1}$ (California/07/2009 strain, MDCK cell line), Influenza Virus Type B (Florida/4/2006 strain, MDCK cell line) using standart AACF screening assay protocols ${ }^{17-19}$. 


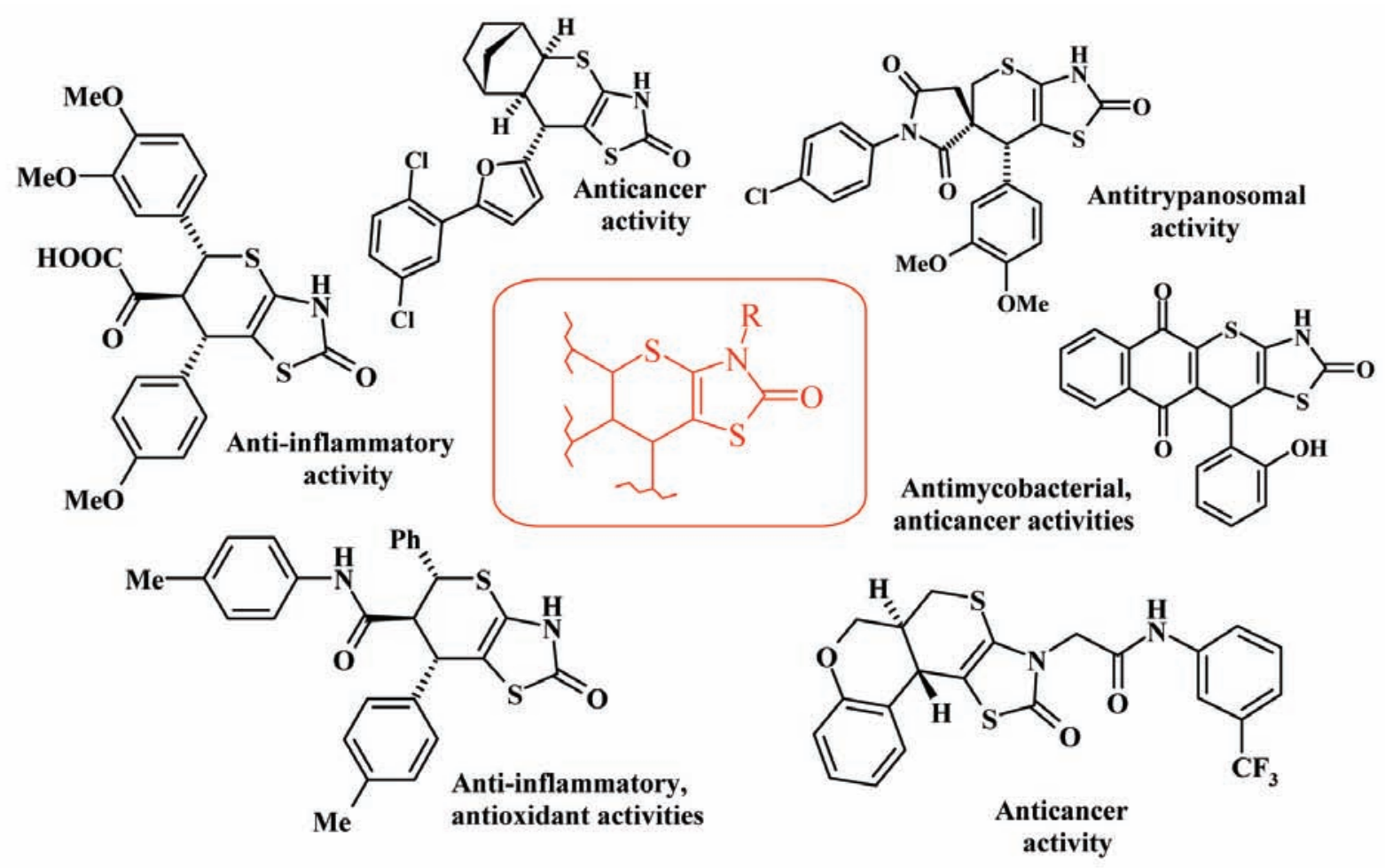

Fig. 1. Biologically active compounds among thiopyrano[2,3-d][1,3]thiazoles<smiles>[R]c1cccc(C2C(C(=O)O)=CSc3[nH]c(=O)sc32)c1</smiles>

1. $\mathrm{R}=4-\mathrm{COOMe}$,

2. $\mathrm{R}=2-\mathrm{OCH}_{2} \mathrm{COOEt}$,

3. $\mathrm{R}=3-\mathrm{OPh}$,

4. $\mathrm{R}=4-\mathrm{t}-\mathrm{Bu}$

5. $\mathrm{R}=2-\mathrm{OH}-3,5-\mathrm{Br}_{2}$<smiles>[R]c1cccc([C@H]2c3sc(=O)[nH]c3SC[C@@]2(CC(=O)O)C(=O)O)c1</smiles>

14. $\mathrm{R}=3,4-(\mathrm{OMe})_{2}$,

15. $\mathrm{R}=3-\mathrm{OMe}-4-\left(3-\mathrm{Cl}-\mathrm{C}_{6} \mathrm{H}_{4}\right)-\mathrm{CH}_{2} \mathrm{O}$,

16. $\mathrm{R}=4-\mathrm{NMe}_{2}$,

17. $\mathrm{R}=4-\mathrm{NEt}_{2}$,

14-17
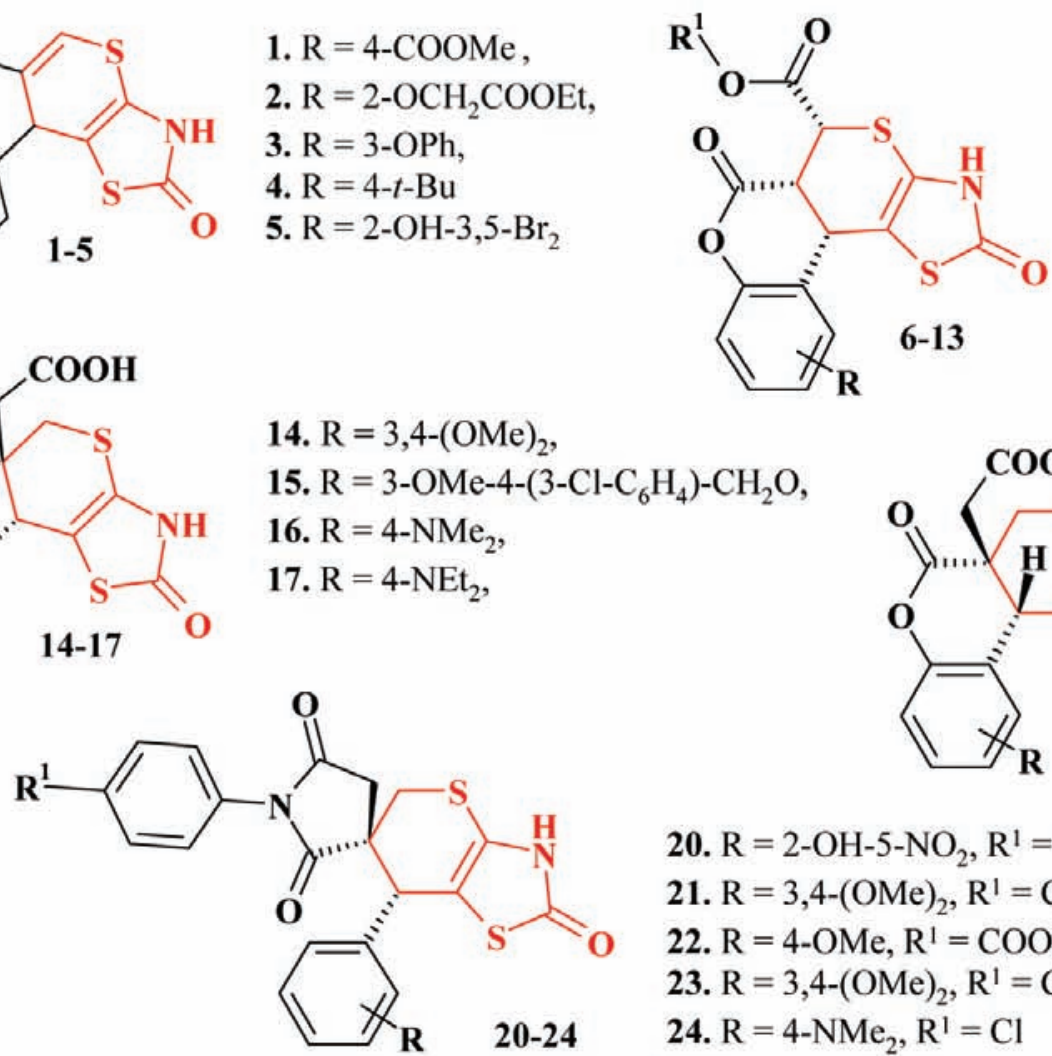

6. $\mathrm{R}=10-\mathrm{NO}_{2}, \mathrm{R}^{1}=\mathrm{H}$

7. $\mathrm{R}=8,10-\mathrm{Br}_{2}, \mathrm{R}^{1}=\mathrm{H}$

8. $\mathrm{R}=\mathrm{H}, \mathrm{R}^{\mathrm{I}}=\mathrm{C}_{7} \mathrm{H}_{15}$

9. $\mathrm{R}=\mathrm{H}, \mathrm{R}^{1}=\mathrm{Et}$

10. $\mathrm{R}=10-\mathrm{NO}_{2}, \mathrm{R}^{1}=\mathrm{Et}$

11. $R=8,10-\mathrm{Br}_{2}, \mathrm{R}^{\mathrm{l}}=\mathrm{Et}$

12. $\mathrm{R}=\mathrm{H}, \mathrm{R}^{1}=\mathrm{Me}$

13. $\mathrm{R}=10-\mathrm{NO}_{2}, \mathrm{R}^{1}=\mathrm{Me}$

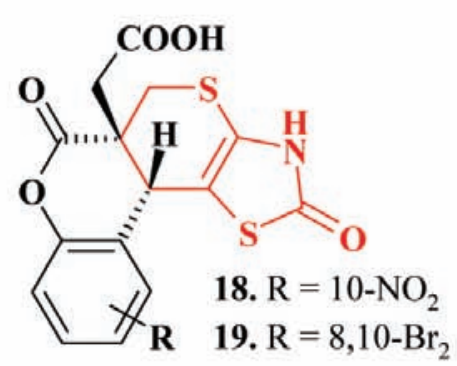

20. $\mathrm{R}=2-\mathrm{OH}-5-\mathrm{NO}_{2}, \mathrm{R}^{1}=\mathrm{Cl}$

21. $\mathrm{R}=3,4-(\mathrm{OMe})_{2}, \mathrm{R}^{\prime}=\mathrm{COOEt}$

22. $\mathrm{R}=4-\mathrm{OMe}, \mathrm{R}^{1}=\mathrm{COOEt}$

23. $\mathrm{R}=3,4-(\mathrm{OMe})_{2}, \mathrm{R}^{\mathrm{I}}=\mathrm{Cl}$

24. $\mathrm{R}=4-\mathrm{NMe}_{2}, \mathrm{R}^{1}=\mathrm{Cl}$

Fig. 2. Compounds tested for antiviral activity 
Antiviral assay. Antiviral assay was performed at a virus's panel with a protocol of the NIAID's antimicrobial acquisition and coordinating ${ }^{17}$. Results for each tested compound were reported as virusinhibitory concentration; $50 \%$ endpoint $\left(\mathrm{EC}_{50}\right)$ and cell-inhibitory concentration, $50 \%$ endpoint $\left(\mathrm{CC}_{50}\right)$ were determined. A general selectivity index (SI) was calculated as a ration of $\left(\mathrm{EC}_{50}\right) /\left(\mathrm{CC}_{50}\right)$. An SI of 3 or greater indicates that confirmatory testing is needed.

\section{Inhibition of Viral Cytopathic Effect (CPE).}

This test, run in 96 well flat-bottomed microplates, was used for the initial antiviral evaluation of compounds. In this CPE inhibition test, four $\log 10 \mathrm{di}-$ lutions of each test compound (e.g. 1000, 100, 10, $1 \mu \mathrm{g} / \mathrm{ml}$ ) were added to 3 cups containing the cell monolayer; within $5 \mathrm{~min}$. On the next step, the virus was added and the plate was sealed and incubated at $37^{\circ} \mathrm{C}$. CPE read microscopically when untreated infected controls develop a 3 to $4+$ CPE (approximately 72 to $120 \mathrm{hr}$ ). A known positive control drug Ribavirin was evaluated in parallel with test drugs in each test. The data are expressed as $50 \%$ effective concentrations $\left(\mathrm{EC}_{50}\right)$.

Increase in Neutral Red (NR) Dye Uptake. This test was run to validate the CPE inhibition seen in the initial test, and utilized the same 96-well micro plates after the CPE has been read. When neutral red was added to the medium cells that were not damaged by virus take up a greater amount of dye, which is desplayed on a computerized microplate autoreader. An $\mathrm{EC}_{50}$ was determined from this dye uptake.

Cytotoxicity. In the CPE inhibition tests, two wells of uninfected cells treated with each concentration of tested compounds was run in parallel with the infected, treated wells. At the time CPE was determined microscopically. The toxicity control cells were also examined microscopically for any changes in cell appearance compared to normal control cells run in the same plate. These changes may be enlargement, granularity, cells with ragged edges, filmy appearance, rounding, detachment from the surface of the well, or other changes. These changes were given a designation of $\mathrm{T}(100 \%$ toxic), $\mathrm{PVH}$ (partially toxic-very heavy $-80 \%$ ), $\mathrm{PH}$ (partially toxic-heavy $-60 \%$ ), P (partially toxic $-40 \%$ ), Ps (partially toxic-slight-20\%), or 0 (no toxicity $-0 \%$ ), conforming to the degree of cytotoxicity seen. A $50 \%$ cell inhibitory (cytotoxic) concentration $\left(\mathrm{CC}_{50}\right)$ was determined by regression analysis of these data.

\section{Results and discussions}

Antiviral activity assay of synthesized compounds allowed us to identify some highly active thiopyrano[2,3- $d]$ thiazoles, which demonstrated certain sensitivity profile towards, Influenza Virus Types $\mathrm{A}_{3} \mathrm{~N}_{2}$ and $\mathrm{H}_{5} \mathrm{~N}_{1}$, as well Dengue Virus. The obtained results are summarized in Table.

Among 2-oxo-3,7-dihydro-2H-thiopyrano[2,3- $d]$ thiazole-6-carboxylic acids (1-5) compound 1 showed a weak activity against Dengue Virus $\left(\mathrm{EC}_{50}=71 \mu \mathrm{g} / \mathrm{ml}, \mathrm{SI}>1.4\right)$, and derivatives 3-5 exhibited an efficiency against Venezuelan Equine Encephalitis Virus $\left(\mathrm{EC}_{50}=21 \div 45 \mu \mathrm{g} /\right.$ $\mathrm{ml}, \mathrm{SI}=1,1 \div 1,7)$, Dengue Virus $\left(\mathrm{EC}_{50}=18 \div 32 \mu \mathrm{g} /\right.$ $\mathrm{ml}$, SI $=1,0 \div 1,1)$, Respiratory Syncytial Virus $\left(\mathrm{EC}_{50}=26 \mu \mathrm{g} / \mathrm{ml}, \mathrm{SI}=1,1 \div 3,8\right)$, SARS Coronavirus $(\mathrm{SI}=1,2 \div 2,3)$. The substituents in the positions 3,4 and 5 of aryl frgment contributed to increase of antiviral activity for a above-mentioned group of compounds. Moderate effect against influenza virus A $\left(\mathrm{H}_{5} \mathrm{~N}_{1}\right.$, Vietnam strain) is identified for derivative $4\left(\mathrm{EC}_{50}=3.6 \div 6.8 \mu \mathrm{g} / \mathrm{ml}\right.$ and $\left.\mathrm{SI}=5.0 \div 8.9\right)$.

According to the results of study compounds 14-17 haven't shown an antiviral effect, in the same time tetracyclic derivatives 18 and 19 pocessed a weak activity against influenza virus $\mathrm{A}\left(\mathrm{H}_{5} \mathrm{~N}_{1}\right.$, Vietnam strain). It has been identified compound 20 among 7',-(R-phenyl)-1-(R ${ }^{1}$-phenyl)-3',7',-dihydro$2 H, 2^{\prime}, H, 5 H$-spiro[pyrolidin-3,6',-thiopyrano[2,3-d] thiazol]-2,2',5-triones (20-24), which had some activity against Dengue virus $\left(\mathrm{EC}_{50}=8 \div 18 \mu \mathrm{g} /\right.$ $\mathrm{ml}, \mathrm{SI}=4,7 \div>13.0$ ). Other viruses were resistant to the action of compounds 20-24. The SAR study revealed that combination of a chlorine atom in the para-position of the 1-aryl substituent and 2-hydroxy-5-nitrophenyl (20), 4-methoxyphenyl (23), and 4-dimethylaminophenyl (24) fragments in position 7 of basic heterocycle are important for new antiviral thiopyrano[2,3- $d]$ thiazoles design.

Derivatives of rel-(5R,5aR,11bS)-2,6-dioxo3,5a,6,11b-tetrahydro- $2 H, 5 H$-chromeno[ $\left[4^{\prime}, 3^{\prime}: 4,5\right]$ thiopyrano[2,3- $d][1,3]$ thiazole-5-carboxylic acids (6-13) belong to the most promising group of compounds. The substituents in the positions 8 and 10 of the basic tetracyclic heterosystem and the ester group in position 5 are desirable for antiviral activity. It was found, the increase of the alkyl moiety length for alkyl rel-(5R,5aR,11bS)-2,6-dioxo3,5a,6,11b-tetrahydro- $2 H, 5 H$-chromeno[4',3':4,5] thiopyrano[2,3- $d][1,3]$ thiazole-5-carboxylates (8-13) 
Ta ble. Antiviral activity of the synthesized compounds ${ }^{a}$

\begin{tabular}{|c|c|c|c|c|c|}
\hline $\begin{array}{l}\text { Com- } \\
\text { pound }\end{array}$ & Virus / strain / cell line & Method $^{b}$ & $\begin{array}{l}\mathrm{EC}_{50}{ }^{\mathrm{c}}, \\
\mu \mathrm{g} / \mathrm{ml}\end{array}$ & $\begin{array}{l}\mathrm{CC}_{50}{ }^{\mathrm{d}}, \\
\mu \mathrm{g} / \mathrm{ml}\end{array}$ & $\mathrm{SI}^{\mathrm{e}}$ \\
\hline 1 & Dengue Virus Type 2 / New Guinea C / Vero 76 & NR & 71 & $>100$ & $>1.4$ \\
\hline \multirow[t]{7}{*}{3} & $\begin{array}{l}\text { Venezuelan Equine Encephalitis } \\
\text { Virus / TC - } 83 \text { / Vero }\end{array}$ & NR & 35 & 59 & 1.7 \\
\hline & \multirow{2}{*}{ Dengue Virus Type 2 / New Guinea C / Vero 76} & NR & 32 & 34 & 1.1 \\
\hline & & $\mathrm{V}$ & 18 & 32 & 1.8 \\
\hline & Flu B / Florida /4/2006/ MDCK & NR & 32 & 39 & 1.2 \\
\hline & Respiratory Syncytial Virus / A2 / MA 104 & $\mathrm{~V}$ & 32 & $>100$ & $>3.1$ \\
\hline & \multirow{2}{*}{ SARS CoV / Urbani / Vero 76} & NR & 26 & 33 & 1.3 \\
\hline & & $\mathrm{V}$ & 56 & $>100$ & $>1.8$ \\
\hline \multirow[t]{8}{*}{4} & \multirow{2}{*}{$\begin{array}{l}\text { Venezuelan Equine Encephalitis } \\
\text { Virus / TC - } 83 \text { / Vero }\end{array}$} & NR & 24 & 35 & 1.5 \\
\hline & & $\mathrm{V}$ & 21 & 28 & 1.3 \\
\hline & \multirow{2}{*}{ Flu A $\left(\mathrm{H}_{5} \mathrm{~N}_{1}\right) /$ Vietnam /1203/2004H / MDCK } & NR & 6.8 & 34 & 5.0 \\
\hline & & $\mathrm{V}$ & 3.6 & 32 & 8.9 \\
\hline & \multirow{2}{*}{ Flu B / Florida /4/2006/ MDCK } & NR & 30 & 41 & 1.4 \\
\hline & & $\mathrm{V}$ & 32 & $>100$ & $>3.1$ \\
\hline & Rift Valley Fever Virus / MP -12 / Vero 76 & NR & 28 & 41 & 1.5 \\
\hline & SARS CoV / Urbani / Vero 76 & NR & 32 & 38 & 1.2 \\
\hline \multirow[t]{10}{*}{5} & $\begin{array}{l}\text { Venezuelan Equine Encephalitis } \\
\text { Virus / TC - } 83 \text { / Vero }\end{array}$ & NR & 45 & 50 & 1.1 \\
\hline & \multirow{2}{*}{ Dengue Virus Type 2 / New Guinea C / Vero 76} & NR & 32 & 36 & 1.1 \\
\hline & & $\mathrm{V}$ & 32 & 32 & 1.0 \\
\hline & Tacaribe Virus / TRVL -11573 / Vero & NR & 40 & 53 & 1.3 \\
\hline & Rift Valley Fever Virus / MP -12 / Vero 76 & NR & 26 & 36 & 1.4 \\
\hline & \multirow{2}{*}{ Respiratory Syncytial Virus / A2 / MA 104} & NR & 26 & $>100$ & $>3.8$ \\
\hline & & $\mathrm{V}$ & 37 & $>100$ & 2.7 \\
\hline & Flu A $\left(\mathrm{H}_{3} \mathrm{~N}_{2}\right) /$ Perth /16/2009 / MDCK & NR & 32 & 43 & 1.3 \\
\hline & \multirow{2}{*}{ SARS CoV / Urbani / Vero 76} & NR & 27 & 63 & 2.3 \\
\hline & & $\mathrm{V}$ & 32 & 68 & 2.1 \\
\hline \multirow[t]{4}{*}{6} & $\begin{array}{l}\text { Venezuelan Equine Encephalitis } \\
\text { Virus / TC - } 83 \text { / Vero }\end{array}$ & NR & 41 & 58 & 1.4 \\
\hline & Flu B / Florida /4/2006/ MDCK & NR & 29 & $>100$ & $>3.4$ \\
\hline & \multirow{2}{*}{ Flu A $\left(\mathrm{H}_{1} \mathrm{~N}_{1}\right) /$ California /07/2009/ MDCK } & NR & 54 & $>100$ & $>1.9$ \\
\hline & & $\mathrm{V}$ & 100 & $>100$ & $>1.0$ \\
\hline
\end{tabular}




\section{Ta ble. Continuation}

\begin{tabular}{|c|c|c|c|c|c|}
\hline \multirow[t]{11}{*}{7} & \multirow{2}{*}{$\begin{array}{l}\text { Venezuelan Equine Encephalitis } \\
\text { Virus / TC - } 83 \text { / Vero }\end{array}$} & NR & 24 & 65 & 2.7 \\
\hline & & $\mathrm{V}$ & 27 & 42 & 1.6 \\
\hline & Dengue Virus Type 2 / New Guinea C / Vero 76 & $\mathrm{~V}$ & 32 & 42 & 1.3 \\
\hline & \multirow{2}{*}{ Flu A $\left(\mathrm{H}_{5} \mathrm{~N}_{1}\right) /$ Vietnam /1203/2004H / MDCK } & NR & 3.1 & 45 & 15 \\
\hline & & $\mathrm{V}$ & 10 & 32 & 3.2 \\
\hline & \multirow{2}{*}{ Flu B / Florida /4/2006/ MDCK } & NR & 8.8 & 18 & 2.0 \\
\hline & & $\mathrm{V}$ & 13 & 24 & 1.8 \\
\hline & Flu A $\left(\mathrm{H}_{1} \mathrm{~N}_{1}\right) /$ California /07/2009/ MDCK & NR & 31 & 37 & 1.2 \\
\hline & \multirow{2}{*}{ Flu A $\left(\mathrm{H}_{3} \mathrm{~N}_{2}\right) /$ Perth /16/2009 / MDCK } & NR & 35 & 49 & 1,4 \\
\hline & & $\mathrm{V}$ & 32 & $>100$ & 3.1 \\
\hline & SARS CoV / Urbani / Vero 76 & $\mathrm{~V}$ & 42 & $>100$ & $>2.4$ \\
\hline \multirow[t]{9}{*}{8} & \multirow{2}{*}{ Flu A $\left(\mathrm{H}_{5} \mathrm{~N}_{1}\right) /$ Vietnam /1203/2004H / MDCK } & NR & 32 & $>100$ & 3,1 \\
\hline & & $\mathrm{V}$ & 32 & $>100$ & 3,1 \\
\hline & \multirow{2}{*}{ Flu B / Florida /4/2006/ MDCK } & NR & 32 & $>100$ & 3.1 \\
\hline & & $\mathrm{V}$ & 32 & $>100$ & 3.1 \\
\hline & Tacaribe Virus / TRVL -11573 / Vero & NR & 57 & 60 & 1.1 \\
\hline & \multirow{2}{*}{ Flu A $\left(\mathrm{H}_{3} \mathrm{~N}_{2}\right) /$ Perth /16/2009 / MDCK } & NR & 0.6 & $>100$ & $>170$ \\
\hline & & $\mathrm{V}$ & 2,5 & $>100$ & $>40$ \\
\hline & \multirow{2}{*}{ SARS CoV / Urbani / Vero 76} & NR & 56 & $>100$ & $>1.8$ \\
\hline & & V & 23 & 28 & 1.2 \\
\hline \multirow[t]{5}{*}{10} & $\begin{array}{l}\text { Venezuelan Equine Encephalitis } \\
\text { Virus / TC - } 83 \text { / Vero }\end{array}$ & NR & 77 & $>100$ & $>1.3$ \\
\hline & Flu A $\left(\mathrm{H}_{5} \mathrm{~N}_{1}\right) /$ Vietnam /1203/2004H / MDCK & NR & 8.0 & $>100$ & $>13$ \\
\hline & Tacaribe Virus / TRVL -11573 / Vero & NR & 50 & $>100$ & $>2.0$ \\
\hline & Rift Valley Fever Virus / MP -12 / Vero 76 & NR & 34 & $>100$ & $>2.9$ \\
\hline & SARS CoV / Urbani / Vero 76 & NR & 48 & $>100$ & $>2.1$ \\
\hline \multirow[t]{7}{*}{11} & \multirow{2}{*}{ Flu A $\left(\mathrm{H}_{5} \mathrm{~N}_{1}\right) /$ Vietnam /1203/2004H / MDCK } & NR & 0.31 & $>100$ & $>320$ \\
\hline & & $\mathrm{V}$ & 0.32 & $>100$ & $>310$ \\
\hline & \multirow{2}{*}{ Flu B / Florida /4/2006/ MDCK } & NR & 34 & $>100$ & $>2.9$ \\
\hline & & $\mathrm{V}$ & 32 & $>100$ & $>3.1$ \\
\hline & \multirow{2}{*}{ Flu A $\left(\mathrm{H}_{1} \mathrm{~N}_{1}\right) /$ California $/ 07 / 2009 / \mathrm{MDCK}$} & NR & 32 & $>100$ & $>3.1$ \\
\hline & & V & 32 & $>100$ & $>3.1$ \\
\hline & Flu A $\left(\mathrm{H}_{3} \mathrm{~N}_{2}\right) /$ Perth /16/2009 / MDCK & NR & 45 & $>100$ & $>2.2$ \\
\hline \multirow[t]{8}{*}{13} & \multirow{2}{*}{ Flu A $\left(\mathrm{H}_{5} \mathrm{~N}_{1}\right) /$ Vietnam /1203/2004H / MDCK } & NR & 32 & $>100$ & $>3.1$ \\
\hline & & $\mathrm{V}$ & 32 & $>100$ & $>3.1$ \\
\hline & \multirow{2}{*}{ Flu B / Florida /4/2006/ MDCK } & NR & 32 & $>100$ & $>3.1$ \\
\hline & & $\mathrm{V}$ & 32 & $>100$ & $>3.1$ \\
\hline & \multirow{2}{*}{ Flu A $\left(\mathrm{H}_{1} \mathrm{~N}_{1}\right) /$ California /07/2009/ MDCK } & NR & 27 & $>100$ & $>3.7$ \\
\hline & & $\mathrm{V}$ & 32 & 100 & 3.1 \\
\hline & \multirow{2}{*}{ Flu A $\left(\mathrm{H}_{3} \mathrm{~N}_{2}\right) /$ Perth /16/2009 / MDCK } & NR & 30 & $>100$ & $>3.3$ \\
\hline & & V & 42 & $>100$ & $>2.4$ \\
\hline
\end{tabular}




\section{Table. Continuation}

\begin{tabular}{|c|c|c|c|c|c|}
\hline 17 & Tacaribe Virus / TRVL -11573 / Vero & NR & 28 & 38 & 1.4 \\
\hline \multirow[t]{3}{*}{18} & Flu A $\left(\mathrm{H}_{5} \mathrm{~N}_{1}\right) /$ Vietnam /1203/2004H / MDCK & NR & 50 & $>100$ & $>2.0$ \\
\hline & \multirow{2}{*}{ Flu A $\left(\mathrm{H}_{1} \mathrm{~N}_{1}\right) /$ California /07/2009/ MDCK } & NR & 32 & $>100$ & $>3.1$ \\
\hline & & $\mathrm{V}$ & 32 & $>100$ & $>3.1$ \\
\hline \multirow[t]{2}{*}{19} & $\begin{array}{l}\text { Venezuelan Equine Encephalitis } \\
\text { Virus / TC -83 / Vero }\end{array}$ & NR & 67 & $>100$ & $>1.5$ \\
\hline & Flu A $\left(\mathrm{H}_{5} \mathrm{~N}_{1}\right) /$ Vietnam /1203/2004H / MDCK & NR & 31 & $>100$ & $>3.2$ \\
\hline \multirow[t]{5}{*}{20} & \multirow{2}{*}{ Dengue Virus Type 2 / New Guinea C / Vero 76} & NR & 18 & 84 & 4.7 \\
\hline & & $\mathrm{V}$ & 8 & $>100$ & $>13$ \\
\hline & Flu A $\left(\mathrm{H}_{5} \mathrm{~N}_{1}\right) /$ Vietnam /1203/2004H / MDCK & NR & 30 & 43 & 1.4 \\
\hline & Tacaribe Virus / TRVL -11573 / Vero & NR & 26 & 56 & 2.2 \\
\hline & Respiratory Syncytial Virus / A2 / MA 104 & NR & 46 & $>100$ & $>2.2$ \\
\hline \multirow[t]{4}{*}{23} & Flu A $\left(\mathrm{H}_{5} \mathrm{~N}_{1}\right) /$ Vietnam /1203/2004H / MDCK & $\mathrm{V}$ & 32 & $>100$ & $>3.1$ \\
\hline & Flu B / Florida /4/2006/ MDCK & NR & 32 & $>100$ & $>3.1$ \\
\hline & \multirow{2}{*}{ Flu A $\left(\mathrm{H}_{1} \mathrm{~N}_{1}\right) /$ California /07/2009/ MDCK } & NR & 27 & $>100$ & $>3.7$ \\
\hline & & $\mathrm{V}$ & 32 & 100 & 3.1 \\
\hline \multirow[t]{4}{*}{24} & Flu A (H5N1) / Vietnam /1203/2004H / MDCK & $\mathrm{V}$ & 32 & $>100$ & 3.1 \\
\hline & Rift Valley Fever Virus / MP -12 / Vero 76 & NR & 23 & 68 & 3.0 \\
\hline & Respiratory Syncytial Virus / A2 / MA 104 & NR & 23 & 50 & 2.2 \\
\hline & SARS CoV / Urbani / Vero 76 & NR & 43 & $>100$ & $>2.3$ \\
\hline \multirow{13}{*}{$\begin{array}{l}\text { Riba- } \\
\text { virin }\end{array}$} & Respiratory Syncytial Virus/ A2 / MA 104 & NR & 6.1 & $>250$ & $>41$ \\
\hline & \multirow{2}{*}{ Rift Valley Fever Virus / MP -12 / Vero 76} & NR & 8.9 & $>1000$ & $>110$ \\
\hline & & $\mathrm{V}$ & 9.1 & $>1000$ & $>110$ \\
\hline & \multirow{2}{*}{ Tacaribe Virus / TRVL -11573 / Vero } & NR & 5.4 & $>1000$ & $>190$ \\
\hline & & $\mathrm{V}$ & 5.6 & $>1000$ & $>180$ \\
\hline & \multirow{2}{*}{ Flu A $\left(\mathrm{H}_{1} \mathrm{~N}_{1}\right) /$ California /07/2009/ MDCK } & NR & 4.9 & $>100$ & $>20$ \\
\hline & & $\mathrm{V}$ & 3.2 & $>100$ & $>31$ \\
\hline & \multirow{2}{*}{ Flu A $\left(\mathrm{H}_{3} \mathrm{~N}_{2}\right) /$ Perth /16/2009 / MDCK } & NR & $>11.0$ & $>100$ & $>9,1$ \\
\hline & & $\mathrm{V}$ & $>11.0$ & $>100$ & $>9.1$ \\
\hline & \multirow{2}{*}{ Flu A $\left(\mathrm{H}_{5} \mathrm{~N}_{1}\right) /$ Vietnam /1203/2004H / MDCK } & NR & 2.3 & $>100$ & $>43.0$ \\
\hline & & $\mathrm{V}$ & 5.3 & $>100$ & $>19$ \\
\hline & \multirow{2}{*}{ Flu B / Florida /4/2006/ MDCK } & NR & 2.4 & $>100$ & $>42$ \\
\hline & & $\mathrm{V}$ & 1.7 & $>100$ & $>59$ \\
\hline
\end{tabular}

${ }^{a}$ Compounds 2, 9, 12, 14-16, 21 and 22 did not show any antiviral activity. ${ }^{b} \mathrm{NR}$ - neutral red, $\mathrm{V}-$ visual $^{\mathrm{c}} \mathrm{EC}_{50}-\mathrm{com}^{\mathrm{b}}$ pound concentration that reduces viral replication by $50 \%{ }^{\mathrm{d}} \mathrm{CC}_{50}-$ compound concentration that reduces cell viability by $50 \%{ }^{\mathrm{e}} \mathrm{SI}-\mathrm{CC}_{50} / \mathrm{EC}_{50}$.

contributes for antiviral activity increasing (Fig. 3). Moreover, two the most active hits $\mathbf{8}$ and $\mathbf{1 1}$ belong to the above-mentioned group of thiopyrano[2,3-d] $[1,3]$ thiazoles. Compound 8 showed a higher activity against Influenza Virus Type $\mathrm{A}\left(\mathrm{H}_{3} \mathrm{~N}_{2}\right.$, Perth strain) with $\mathrm{EC}_{50}=0.6 \div 2.5 \mu \mathrm{g} / \mathrm{ml}$ and $\mathrm{SI}=40.0 \div>170.0$, and derivative $\mathbf{1 1}$ - against Influenza Virus Type A $\left(\mathrm{H}_{5} \mathrm{~N}_{1}\right.$, Vietnam strain) with $\mathrm{EC}_{50}=0.31 \div 0.32 \mu \mathrm{g} / \mathrm{ml}$ and $\mathrm{SI}=>310.0 \div>320.0$.

In general, it should be noted that compounds $6,7,8,10,11,13$ have the specific antiviral activity against influenza viruses. 


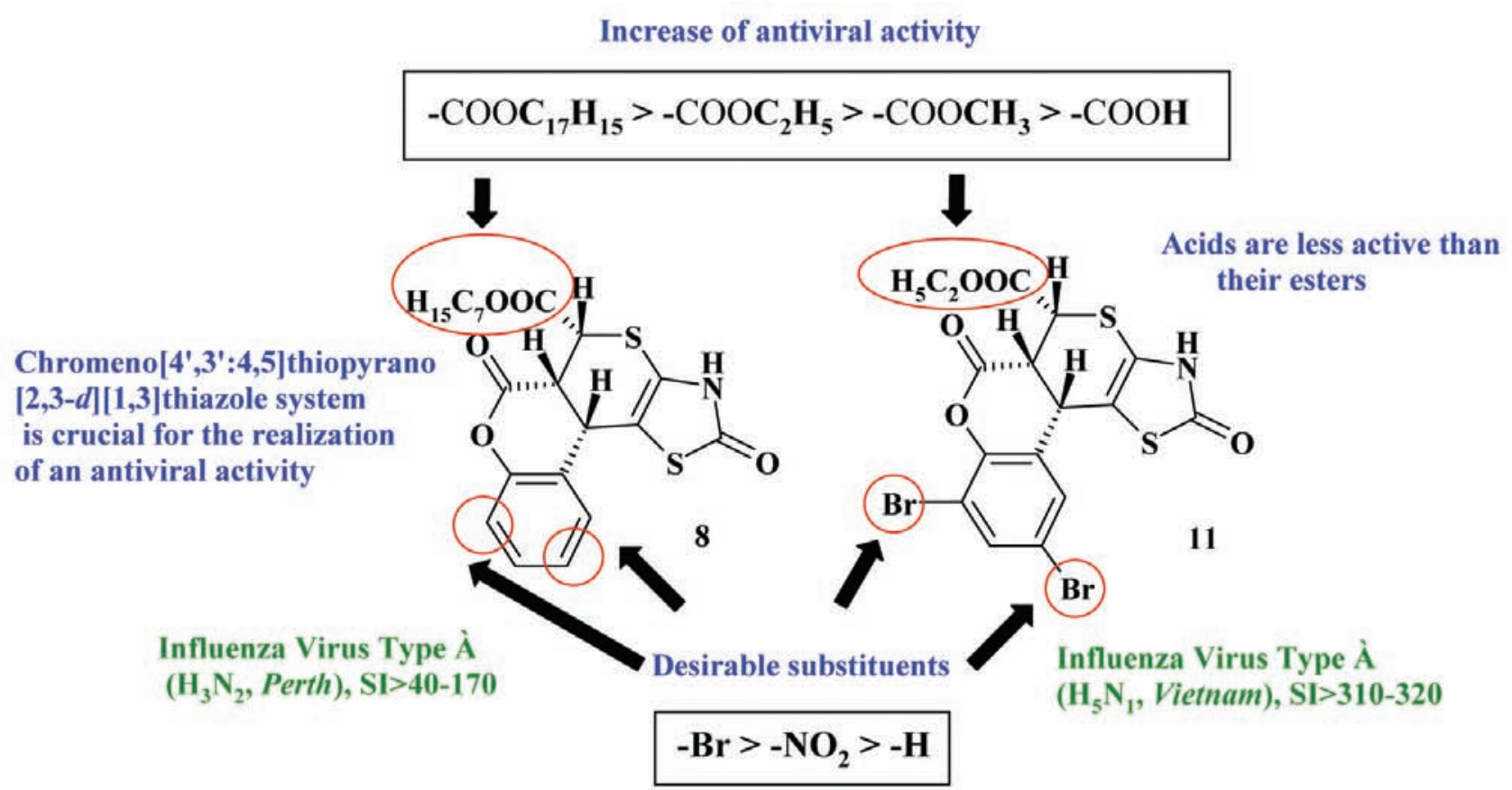

THE MOST ACTIVE COMPOUNDS

Fig. 3. SAR study of the thiopyrano[2,3-d][1,3]thiazoles.

The screening of 24 thiopyrano[2,3- $d][1,3]$ thiazole derivatives against a wide range of viruses has been carried out. Some compounds possess moderate levels of the antiviral activity. However, the preliminary results of antiviral activity allowed to identify the active compounds $\mathbf{8}$ and 11, which have shown the significant antiviral activity against Influenza Virus Type $\mathrm{A}_{3} \mathrm{~N}_{2}$ (Perth strain) and Influenza Virus Type $\mathrm{A}_{5} \mathrm{~N}_{1}$ (Vietnam strain).

Thus, derivatives bearing thiopyrano[2,3-d] $[1,3]$ thiazole fragment could be considered as promising basis for further modification in searching for new antiviral agents.

\section{Acknowledgments}

The authors are grateful to Dr. Chris Tseng, from Division of Microbiology and Infectious Diseases NIAID/NIH, Bethesda, USA, for in vitro evaluation of antiviral activity. Thank you for Cedars Sinai Medical Center's International Research and Innovation in Medicine Program, the Association for Regional Cooperation in the Fields of Health, Science and Technology (RECOOP HST Association) for their support of our organization as participating Cedars - Sinai Medical Center - RECOOP Research Centers (CRRC).

\section{References}

1. Lesyk R, Zimenkovsky B, Atamanyuk D, Jensen F, Kiec-Kononowicz K, Gzella A. Anticancer thiopyrano[2,3-d][1,3]thiazol-2-ones with norbornane moiety. Synthesis, cytotoxicity, physico-chemical properties, and computational studies. Bioorg Med Chem. 2006; 14(15): 52305240.

2. Atamanyuk D, Zimenkovsky B, Lesyk R. Synthesis and anticancer activity of novel thiopyrano[2,3- $d$ ] thiazole-based compounds containing norbornane moiety. J Sulf Chem. 2008; 29(2): 151-162.

3. Zelisko N, Atamanyuk D, Vasylenko O, Gre1 lier Ph, Lesyk R. Synthesis and antitrypanosomal activity of new 6,6,7-trisubstituted thiopyrano[2,3-d][1,3]thiazoles. Bioorg Med Chem Lett. 2012; 22(23): 7071-7074.

4. Atamanyuk D, Zimenkovsky B, Atamanyuk V, Nektegayev I, Lesyk R. Synthesis and biological activity of new thiopyrano[2,3- $d$ ] thiazoles containing a naphthoquinone moiety. Sci Pharm. 2013; 81(2): 423-436.

5. Kryshchyshyn A, Atamanyuk D, Lesyk R. Fused Thiopyrano[2,3-d]thiazole Derivatives as 
Potential Anticancer Agents. Sci Pharm. 2012; 80(3): 509-529.

6. Lozynskyi AV, Kaminskyy DV, Romanchyshyn KhB, Semenciv NG, Ogurtsov VV, Nektegayev IO, Lesyk RB. Screening of antioxidant and anti-inflammatory activities among thiopyrano[2,3-d]thiazoles. Biopolym Cell. 2015; 31(2): 131-137.

7. Lozynskyi A, Zimenkovsky B, Nektegayev I, Lesyk R. Arylidene pyruvic acids motif in the synthesis of new thiopyrano[2,3- $d$ ]thiazoles as potential biologically active compounds. Heterocycl Commun. 2015; 21(1): 55-59.

8. Al-Ansary GH, Ismail MA, El Ella DAA, Eid $\mathrm{S}$, Abouzid KA. Molecular design and synthesis of HCV inhibitors based on thiazolone scaffold. Eur J Med Chem. 2013; 68: 19-32.

9. Talele TT, Arora P, Kulkarni SS, Patel MR, Singh S, Chudayeu M, Kaushik-Basu N. Structure-based virtual screening, synthesis and SAR of novel inhibitors of hepatitis $\mathrm{C}$ virus NS5B polymerase. Bioorgan Med Chem. 2010; 18(13): 4630-4638.

10. Havrylyuk D, Zimenkovsky B, Vasylenko O, Lesyk R. Synthesis and anticancer and antiviral activities of new 2-pyrazoline-substituted 4-thiazolidinones. J Heterocyclic Chem. 2013; 50(S1): E55-E62.

11. Barreca ML, Iraci N, Manfroni G, Cecchetti V. Allosteric inhibition of the hepatitis $\mathrm{C}$ virus NS5B polymerase: in silico strategies for drug discovery and development. Future Med Chem. 2011; 3(8): 1027-1055.

12. Nitsche C, Schreier VN, Behnam MA, Kumar A., Bartenschlager R, Klein CD. Thiazolidinonepeptide hybrids as dengue virus protease inhibitors with antiviral activity in cell culture. J Med Chem. 2013; 56(21): 8389-8403.

13. Jiang S, Tala SR, Lu H, Abo-Dya NE, Avan I, Gyanda K, Lu L, Katritzky A R, Debnath A.
Design, synthesis, and biological activity of novel 5-((arylfuran/1H-pyrrol-2-yl)methylene)-2thioxo-3-(3-(trifluoromethyl)phenyl)thiazolidin4-ones as HIV-1 fusion inhibitors targeting gp41. J Med Chem. 2011; 54(2): 572-579.

14. Kowiel M, Zelisko N, Atamanyuk D. Lesyk R, Gzella AK. 2-[7-(3,5-Dibromo-2hydroxyphenyl)-6-ethoxycarbonyl-2-oxo-5H2,3,6,7-tetrahydrothiopyrano[2,3- $d][1,3]$ thiazol6-yl]acetic acid ethanol monosolvate. Acta Crystallogr E. 2012; E68: 2721-2722.

15. Zelisko N, Atamanyuk D, Vasylenko $\mathrm{O}$, Bryhas A, Matiychuk V, Gzella A, Lesyk R. Crotonic, cynnamic, and propiolic acids motifs in the synthesis of thiopyrano[2,3- $d][1,3]$ thiazoles via hetero-Diels-Alder reaction and related tadem processes. Tetrahedron. 2014; 70(3): 720-729.

16. Zelisko N, Atamanyuk D, Ostapiuk Y, Bryhas A, Matiychuk V, Gzella A, Lesyk R. Synthesis of fused thiopyrano[2,3-d][1,3]thiazoles via heteroDiels-Alder reaction related tandem and domino processes. Tetrahedron. 2015; 71(50): 9501-9508.

17. Sidwell RW, Smee D F. In vitro and in vivo assay systems for study of influenza virus inhibitors. Antiviral Res. 2000; 48: 1-16.

18. Severson WE, Shindo N, Sosa M, Fletcher T, White EL, Ananthan S, Jonsson CB. Development and validation of a high-throughput screen for inhibitors of SARS $\mathrm{CoV}$ and its application in screening of a 100,000-compound library. J Biomol Screen. 2007; 12(1): 33-40.

19. Sidwell RW, Huffman JH. Use of disposable micro tissue culture plates for antiviral and interferon induction studies. Appl Microbiol. 1971; 22(5): 797-801.

Received 25.03.2016 